\title{
The use of spirometers in general practice
}

D Bellamy, G Hoskins, B Smith, F Warner and R Neville, for the General Practitioners in Asthma Group

\section{Abstract}

Objective: $\quad$ To describe the current use of spirometers in primary care in the UK.

Design and A postal questionnaire was sent to all 548 Subjects: members of the GPs in Asthma Group (GPIAG), who have a special interest in asthma, and to 2000 randomly selected GPs throughout the UK.

Results: $\quad$ Responses were received from 349 (64\%) of the GPIAG members and 582 (29\%) of the random group. Spirometers were present in 175 practices $(50 \%)$ of GPIAG members and $186(32 \%)$ of the random group. A hand-held digital spirometer was used by $61 \%$ of all respondents. Only $25 \%$ of GPs without a spirometer wished to buy one, while $60 \%$ would choose an open access hospital service instead.

Centre, 4 Tolpuddle
Gardens, Muscliffe,
Bournemouth BH9 3 LQ

Gaylor Hoskins

Research Co-ordinator

Barbara Smith

Research Co-ordinator

Frances Warner

Research Co-ordinator

Ron Neville

Senior Lecturer

GPIAG Research Unit,

Tayside Centre for General

Practice, University of

Dundee, Dundee DD2 4AD.

Correspondence to:

Dr Bellamy

Asthma in Gen Pract 1997; 5(1): 8-9.

Table 1: Spirometry questionnaire results

\begin{tabular}{|c|c|c|c|}
\hline & $\begin{array}{c}\text { GPIAG } \\
\text { Members }\end{array}$ & $\begin{array}{c}\text { Random } \\
\text { Group }\end{array}$ & Total \\
\hline $\begin{array}{l}\text { Mailed } \\
\text { Responded } \\
\text { Would welcome guidelines } \\
\text { Spirometer owned by practice } \\
\text { Local open access spirometry } \\
\text { service available }\end{array}$ & $\begin{array}{l}548 \\
349(64 \%) \\
325(93 \%) \\
175(50 \%)\end{array}$ & $\begin{array}{l}2000 \\
582(29 \%) \\
541(93 \%) \\
186(32 \%)\end{array}$ & $\begin{array}{l}2548 \\
931(37 \%) \\
866(93 \%) \\
361(39 \%)\end{array}$ \\
\hline $\begin{array}{l}\text { Do not own a spirometer } \\
\text { Of which:- } \\
\text { Prepared to buy } \\
\text { Prefer local service }\end{array}$ & $\begin{array}{r}41(24 \%) \\
103(60 \%)\end{array}$ & $\begin{array}{l}101(26 \%) \\
232(59 \%)\end{array}$ & $\begin{array}{l}142(25 \%) \\
335(60 \%)\end{array}$ \\
\hline $\begin{array}{l}\text { Practices who would own or } \\
\text { would buy a spirometer } \\
\text { Of which:- } \\
\text { Would use practice nurse to } \\
\text { perform test } \\
\text { Would want training for } \\
\text { practice nurse }\end{array}$ & 177 (82\%) & 287 (49\%) & $434(86 \%)$ \\
\hline
\end{tabular}

METHOD AND

Results

A short postal questionnaire was sent to all 548 members of the GPs in Asthma Group (GPIAG), a group of GPs with a special interest in asthma, and 2000 GPs randomly selected, by an independent mailing company, from regions around the UK (the random group). Analysable responses were received from 349 (64\%) of GPIAG members and $582(29 \%)$ of the random group (see Table 1). An overwhelming majority (93\%) of both groups welcomed the guidelines on COPD. Spirometers were available in $175(50 \%)$ of the GPIAG group practices and $186(32 \%)$ of the random group.

A small hand-held electronic digital display spirometer was used by 221 (61\%) of respondents with a spirometer, this being one of the cheapest available. Relatively few, 142 (25\%) of the GPs without a spirometer, showed any inclination to buy one. Open access spirometry service was only available to 103 $(11 \%)$ of practices at their local hospital. Yet 335 $(60 \%)$ of respondents who did not already have a spirometer, if given the choice of buying one or using an open access hospital service, would prefer to send their patients to an open access service.

In primary care, $434(86 \%)$ of the 503 practices who had or were prepared to buy a spirometer, said that the practice nurse would perform the measurements. These nurses require appropriate training, more structured information about the management of COPD and a shift from running pure asthma clinics to airflow obstruction clinics. In total, $453(90 \%)$ of the 503 GPs were willing to send practice nurses on a suitable course.

The survey also investigated the current practice of performing reversibility tests for asthma and COPD (see Table 2). Bronchodilator reversibility tests are more commonly undertaken for patients with asthma than for those with COPD. A metered dose inhaler with a large volume spacer is the preferred route of administering a $\beta_{2}$-agonist bronchodilator - a seemingly appropriate choice. The majority, 653 (85\%) of the 764 respondents, used a $\beta_{2}$-agonist $(400 \mathrm{mcg}$ ) for the purpose of reversibility testing.

Reversibility testing with corticosteroids was far less frequently performed by all doctors surveyed, most frequently for suspected COPD. Three hundred and eight of the $931(33 \%)$ respondents routinely carried out oral steroid reversibility testing (see Table 2) of whom 273 $(87 \%)$ used doses of at least $30 \mathrm{mg}$ prednisolone per day. One hundred and five $(67 \%)$ of the random group gave a steroid challenge for less than 14 days compared with 57 $(38 \%)$ of the GPIAG group.

DisCUSSION

This study demonstrates a need for COPD guidelines. However, the data suggest major cost and staff implications for secondary care once BTS recommendations for more widespread use of spirometry are put in place. Currently, spirometry is infrequently used in primary care and it is likely that considerable training would be required for doctors and nurses before this can be increased. In fact, most GPs surveyed would delegate spirometry measurement to their practice nurses, who will clearly need training in the technique and interpretation of spirometry results. However, given a choice, this survey suggests that the majority of GPs $(60 \%)$ would opt for a 
local open access spirometry service rather than buy a spirometer. Only $11 \%$ of practices surveyed currently have this service available. Thus, there will need to be a major expansion in open access services, which will have corresponding cost implications for secondary care equipment and staffing levels.

Our results indicate that steroid challenge tests are performed infrequently and for an inadequate time period. It is known that patients who respond to inhaled bronchodilators do not necessarily respond to inhaled steroids, and therefore many patients are prescribed these drugs inappropriately. ${ }^{6}$ Patients with moderate to severe COPD warrant a formal trial of corticosteroids, for example prednisolone $30 \mathrm{mg}$ daily for at least two weeks. Patients who respond with an increased $\mathrm{FEV}_{1}$ of more than $200 \mathrm{ml}$ will benefit from taking inhaled steroids long-term.

We accept the inherent problem of enthusiast bias in the case of postal questionnaires; individuals with a personal interest in respiratory disease are more likely to respond. This might explain the unexpectedly high figure for spirometer use found in this random sample of GPs. However, this survey probably denotes current best practice in spirometry usage within primary care.

Spirometry is the most appropriate investigation in COPD. It may also allow more effective screening of asymptomatic smokers with the major incentive of preventing disease. Over a period of time reduced smoking could result in savings in hospital care and time off work, but may also help to reduce morbidity from cardiovascular disease.
CONCLUSION Table 2: Reversibility testing

Spirometry is under-used in general practice and many GPs would prefer to use a hospital open access service rather than

buy a spirometer.

This implies an increased

\begin{tabular}{|c|c|c|c|}
\hline & $\begin{array}{c}\text { GPIAG } \\
\text { Members } \\
\mathrm{n}=349\end{array}$ & $\begin{array}{c}\text { Random } \\
\text { Group } \\
n=582\end{array}$ & $\begin{array}{c}\text { Total } \\
\mathrm{n}=931\end{array}$ \\
\hline \multirow{2}{*}{$\begin{array}{l}\text { Routine use of bronchodilator } \\
\text { reversibility for:- } \\
\text { Asthma } \\
\text { COPD } \\
\text { Standard dose of bronchodilator }\end{array}$} & 280 (80\%) & 484 (83\%) & 764 (82\%) \\
\hline & $\begin{array}{l}270(96 \%) \\
220(79 \%) \\
204(73 \%)\end{array}$ & $\begin{array}{l}471(97 \%) \\
376(78 \%) \\
449(93 \%)\end{array}$ & $\begin{array}{l}741(97 \%) \\
596(78 \%) \\
653(85 \%)\end{array}$ \\
\hline \multirow{3}{*}{$\begin{array}{l}\text { Routine use of oral steroid } \\
\text { reversibility for:- } \\
\text { Asthma } \\
\text { COPD } \\
\text { Dose of prednisolone above } \\
30 \mathrm{mg} / \mathrm{day} \\
\text { Test lasts < } 14 \text { days }\end{array}$} & $152(44 \%)$ & $156(27 \%)$ & $308(33 \%)$ \\
\hline & $\begin{array}{r}87(57 \%) \\
133(88 \%) \\
135(89 \%)\end{array}$ & $\begin{array}{l}109(70 \%) \\
123(79 \%) \\
138(88 \%)\end{array}$ & $\begin{array}{l}196(64 \%) \\
256(83 \%) \\
273(89 \%)\end{array}$ \\
\hline & 57 (38\%) & $105(67 \%)$ & 162 (53\%) \\
\hline
\end{tabular}

need for training and expansion of hospital spirometry services in the future.

Conflict of interest: None.

Funding: This study was supported by an educational grant from Glaxo Wellcome.

\section{References}

1. British Thoracic Society guidelines on COPD (1997 in press).

2. ERS - Consensus Statement. Optimal assessment and

management of chronic obstructive pulmonary disease (COPD).

Eur Respir J 1995; 8: 1398-420.

3. Quanjer P H, Tammeling G J, Cotes J E et al. Lung volumes and forced ventilatory flows. Eur Respir J 1993; 6 (S16): 5-40.

4. Fletcher C, Peto R. The natural history of chronic airflow obstruction. BMJ 1977; 1: 1645-8.

5. Office of Population Censuses \& Surveys Mortality Statistics,

Cause: England \& Wales 1992; Series DH@No 19. HMSO,

London, 1993

6. Dow 1, Coggon D, Holgate S T. Respiratory symptoms as predictors of airways lability in the elderly population. Respir Med 1992; 86: 27-32.

\title{
Is childhood pneumonia an unrecognised presentation of asthma?
}

\author{
C E Clark
}

AbSTRact

Background: Personal experience suggests that some children presenting with pneumonia may have undiagnosed asthma.

Objective: To determine the frequency with which asthma is diagnosed following pneumonia.

Method: Retrospective review of the hospital records of 99 children, aged under 17 years, admitted to hospital with pneumonia.

Results: Twenty eight per cent of the children were asthmatic; one third of these (i.e. nine per cent of patients) were newly diagnosed in the six weeks following discharge. Asthmatics were older than the non-asthmatics presenting with pneumonia, and were more likely to have a family history of asthma or personal history of atopy.

Conclusion: Routine follow-up of children admitted with pneumonia can identify new cases of asthma and a high index of suspicion is recommended.

\section{INTRODUCTION}

Asthma is a common childhood disorder. Episodic wheeze and cough at night have been documented as markers of asthma. ${ }^{1}$ However, $25 \%$ of asthmatics do not wheeze prior to diagnosis ${ }^{2}$ and this may lead to delays in diagnosis. ${ }^{3}$ Asthma has been under-diagnosed in children ${ }^{4}$ and recognition of markers other than wheeze ${ }^{5}$ (see Table 1), may help to remedy this. Our clinical experience has shown that young asthmatic patients are sometimes diagnosed following an episode of pneumonia and we considered that pneumonia itself may be a marker for undiagnosed asthma. Little in the available literature directly addresses this hypothesis, so the following pilot study was undertaken to establish how often asthma is diagnosed shortly after an episode of pneumonia.

\section{MeTHOD}

We retrospectivly reviewed the hospital discharge records of all patients aged under 17 years, who had been admitted to the Royal Devon \& Exeter District Hospital (serving a population of 250000) with pneumonia between January 1989 and July 1991. Records were examined retrospectively for: age; sex;

\author{
Christopher Clark \\ Registrar \\ Department of Respiratory \\ Medicine, Royal Devon \& \\ Exeter Hospital (Wonford) \\ Barrack Road, Exeter \\ Devon EX2 5DW. \\ Correspondence to: \\ School Surgery, Fore Street, \\ Witheridge, Devon \\ EX16 8AH.
}

Asthma in Gen Pract 1997; 5(1): 9-11. 